\title{
A study on management of neglected shaft femur fractures by open intramedullary nailing
}

\author{
Wazir Fahad Jan, Alamgir Jahan*, Mohd Yahya Dar, Firdous Ahmad Bangaroo, Imran Khan
}

Department of Orthopaedics, SHKM GMC Nalhar, NUH, Haryana, India

Received: 25 April 2018

Revised: 30 May 2018

Accepted: 31 May 2018

\section{*Correspondence:}

Dr. Alamgir Jahan,

E-mail: fahadwzr94@gmail.com

Copyright: (c) the author(s), publisher and licensee Medip Academy. This is an open-access article distributed under the terms of the Creative Commons Attribution Non-Commercial License, which permits unrestricted non-commercial use, distribution, and reproduction in any medium, provided the original work is properly cited.

\section{ABSTRACT}

Background: Fracture shaft of femur is a common and major musculoskeletal injury and in most of the cases the patients are immediately brought to hospitals for specialist orthopaedic management. However, it is not uncommon in developing countries especially in rural India for these injuries to be neglected initially due to the wide spred practice of quackery. The purpose of this study was to evaluate the effectiveness of open intramedullary nailing in the management of neglected fracture shaft femur patients in relation to achievement of union and functional results.

Methods: This was a prospective observational study conducted on 20 patients presenting to the Orthopaedic OPD of SHKM Government Medical College Hospital, Nalhar, Nuh, Haryana between August 2013 and December 2016, with a diagnosis of neglected fracture shaft of femur. All the patients underwent single stage open reduction and internal fixation with interlocking intramedullary nails. The patients were followed up for a period of 1 year. The patients were analysed for union and functional results.

Results: All the fractures united and the average time of union was 22.6 weeks. The average range of motion of the knees improved from 34 degrees in the preoperative period to 114.5 degrees in the postoperative period. Two patients developed superficial infections at the incision site which resolved with local drainage and oral antibiotics. All the patients were able to return to their preinjury occupation.

Conclusions: Thus results of our study demonstrate that single stage open intramedullary nailing is a safe and effective surgical procedure for the treatment of neglected fractures of shaft of femur.

Keywords: Fracture shaft of femur, Open reduction, Intramedullary, Interlocking nail, Union

\section{INTRODUCTION}

Fractures of the shaft of the femur are among the most common fractures encountered in orthopaedic practice. Because the femur is the largest bone of the body and one of the principal load-bearing bones in the lower extremity, fractures can cause prolonged morbidity and extensive disability unless treatment is appropriate. In developed countries, patients typically present early for treatment and therefore neglected fractures seldom are seen. However, this is not always the case in underdeveloped countries, and neglected femoral fractures remain a problem in the developing world due to the widespread practice of quackery. These neglected patients report later for specialist orthopaedic management with significant morbidity. Closed interlocking intramedullary nailing currently is considered to be the treatment of choice for most acute femoral shaft fractures and, the effectiveness of this procedure has been documented over the years by several studies. $^{1-5}$

However in neglected cases of fracture shaft of femur, closed interlocking intramedullary nailing is not possible due to fracture overriding, soft tissue interposition and fibrous tissue formation at the fracture site. In these 
patients, there is also associated knee joint stiffness and shortening which has to be corrected. The advantages of open nailing in these patients include, easier attainment of absolute anatomical reduction, precise interdigitation of the fracture fragments which improves rotational stability, ease of opening of the medullary canals of the sclerotic bone and rare incidence of rotational malalignment. Thus in the neglected cases of fracture shaft of femur open reduction and internal fixation with interlocking intramedullary nailing is the treatment of choice. Several studies have demonstrated the effectiveness of open intramedullary nailing of femur, especially in neglected cases. ${ }^{6-8}$

In the present study we evaluated the effectiveness of single stage open interlocking intramedullary nailing in neglected fracture shaft of femur patients through the assessment of attainment of union of the fracture and functional results of the limb.

\section{METHODS}

After approval by the institutional ethics committee and informed written consent, the study was started. This was a prospective observational study conducted on 20 patients of either sex with an average age of 26 years, presenting to the Orthopaedic OPD of SHKM Government Medical College Hospital, Nalhar, Nuh, Haryana between August 2013 and December 2016, with a diagnosis of neglected fracture shaft of femur. The sex distribution was 15 males and 5 females. The average time from the occurrence of fracture to treatment was 12 weeks

Inclusion criteria: The inclusion criteria for the diagnosis of neglected fracture shaft of femur were set as a minimum of 4 weeks duration from the injury, with the patient either receiving no treatment at all or treatment received from a quack or local bone setter, at the time of presentation in our OPD, of either sex and with the age of 16 years or above.

Exclusion criteria: Mal-united fractures and non-unions after operative interventions and patients with the age of less than 16 years were excluded from the study.

All the patients were admitted after thorough preoperative workup and preanaesthetic examination. All the patients underwent preoperative anteroposterior and lateral radiographs of the femur, and the range of motion of the knees was measured with a goniometer.

\section{Surgical technique}

After administration of spinal anaesthesia, the patient was placed in lateral position on the fluorescent operating table. Standard lateral approach to femur was used. Longitudinal lateral skin incision was given around the fracture site, tensor fascia lata was cut, vastus lateralis was split and the fracture site was exposed. The callus formed at the fracture site was removed and preserved for later insertion. Fracture ends were exposed and the fibrous tissue was removed from them. Freshening of the bony ends was done by removal of sclerotic bone with a bone nibbler and curette till bleeding surfaces were exposed. Release of soft tissue contractures was done. The medullary canals were opened by drilling. Both proximal and distal ends were reamed with successively increasing diameter reamers. The entry portal for the nail was made in a retrograde fashion with a sharp reamer inserted from distal to proximal direction with the hip in flexion and adduction and incision given at the site of exit of the reamer proximal to the greater trochanter. A guidewire was inserted from the entry portal upto just proximal to the fracture site. Both the fracture ends were held with bone holding clamps and approximated with angulation. Maintaining this position, reduction was done gradually allowing the soft tissues to stretch and guidewire was inserted into the distal fragment. Interlocking nail of appropriate size was selected and inserted in antegrade direction with the help of zig. Alignment, rotation and axial stability were checked. Proximal locking was done with the help of zig and distal locking was done free hand with the help of image intensifier. Manipulation of the knee was done to obtain the range of motion. Haemostasis was achieved. Thorough lavage of the wound was done and callus removed earlier was inserted into the fracture site. Suction drain was kept in place and wound was closed back in layers. Antiseptic dressing was done and the patient was shifted out of the operation theatre.

Standard postoperative care pathway was followed for these patients. The drains were removed after 48 hours and postoperative AP and lateral radiographs were taken. Knee range of motion was started and non-weight bearing ambulation with walker was allowed. The average duration of hospital stay was 8 days. 5 patients required blood transfusions. At the time of discharge patients were instructed about physiotherapy and weight bearing protocols. The sutures were removed after 15 days of surgery. For the first 2 months patients were asked to follow up at 2 week intervals and later on once a month for a period of 1 year following surgery. At follow ups standard AP and lateral radiographs of femur were taken and range of motion of knee was measured using a goniometer. Weight bearing was gradually increased according to callus formation visible on radiographs. Walking aids were discarded at 6 to 8 weeks after surgery. The fracture was defined as united if a minimum of 3 cortices showed bridging callus on radiographs. The patients were followed up for a period of 1 year and after this period all the data collected was subjected to analysis.

\section{Statistical analysis}

Simple arithmetic mean was used for the description of the results of various values of time taken (in weeks) for union and range of motion of the knee (in degrees). 


\section{RESULTS}

This was a prospective observational study. The fractures of all the patients in this study united with an average duration of 22.6 months. The average range of motion of the knees of these patients improved from 34 degrees in the preoperative period to 114.5 degrees in the postoperative period. Sixteen, out of the twenty patients attained full range of motion of the knee. Four patients had residual knee stiffness and three of them improved with physiotherapy and complex passive motion, while one patient required quadricepsplasty.

Table 1: Age distribution of patients.

\begin{tabular}{|lll|}
\hline Age in years & No. of patients & Percentage $(\%)$ \\
\hline $\mathbf{1 6 - 2 0}$ & 4 & 20 \\
\hline $\mathbf{2 1 - 2 5}$ & 4 & 20 \\
\hline $\mathbf{2 6 - 3 0}$ & 9 & 45 \\
\hline $\mathbf{3 1 - 3 5}$ & 2 & 10 \\
\hline $\mathbf{3 6 - 4 0}$ & 1 & 5 \\
\hline Total & 20 & 100 \\
\hline
\end{tabular}

Table 2: Sex distribution.

\begin{tabular}{|lll|}
\hline Gender & No. of patients & Percentage $(\%)$ \\
\hline Male & 15 & 75 \\
\hline Female & 5 & 25 \\
\hline Total & 20 & 100 \\
\hline
\end{tabular}

Table 3: Occupation of the patients.

\begin{tabular}{|lll|}
\hline Occupation & No. of patients & Percentage $(\%)$ \\
\hline Driver & 4 & 20 \\
\hline Farmer & 3 & 15 \\
\hline Student & 2 & 10 \\
\hline Housewife & 5 & 25 \\
\hline Cobbler & 1 & 5 \\
\hline Mechanic & 2 & 10 \\
\hline Sweeper & 1 & 5 \\
\hline Labourer & 2 & 10 \\
\hline Total & 20 & 100 \\
\hline
\end{tabular}

Table 4: Mode of injury of the patients.

\begin{tabular}{|lll|}
\hline $\begin{array}{l}\text { Mode of injury } \\
\text { Road traffic } \\
\text { accident }\end{array}$ & 15 & 75 \\
\hline $\begin{array}{l}\text { Fall from } \\
\text { height }\end{array}$ & 3 & 15 \\
\hline Fall due to slip & 1 & 5 \\
\hline Hit by buffalo & 1 & 5 \\
\hline Total & 20 & 100 \\
\hline
\end{tabular}

There were no neurovascular complications and no apparent limb length discrepancies in our patients. Two patients developed superficial skin infections at the incision site which resolved with oral antibiotics and local drainage. All the patients at follow up were able to return to their preinjury occupation.

Table 5: Table depicting the results of the study.

\begin{tabular}{|lllll|}
\hline Parameter & $\begin{array}{l}\text { Interval from injury to } \\
\text { treatment in weeks }\end{array}$ & $\begin{array}{l}\text { Time taken for the union } \\
\text { of the fracture in weeks }\end{array}$ & $\begin{array}{l}\text { Preoperative knee } \\
\text { flexion in degrees }\end{array}$ & $\begin{array}{l}\text { Postoperative knee } \\
\text { flexion in degrees }\end{array}$ \\
\hline $\begin{array}{l}\text { Mean value of } \\
\text { the parameter }\end{array}$ & 12 & 22.6 & 34 & 114.5 \\
\hline
\end{tabular}

\section{DISCUSSION}

Neglected fractures of the shaft of femur, although a rarity in the developed world are not an uncommon entity in the developing countries, especially in the rural areas. The main reason for this phenomenon is poor socioeconomic status, illiteracy and widespread prevalence of quacks and tradional bone setters. ${ }^{9,10}$ These fractures present a unique challenge to the orthopaedic surgeon as most of these patients have significant morbidity and functional disability. Although closed interlocking intramedullary nailing is now the standard method of treatment of most of the fresh fractures of the shaft of femur, but in the neglected cases this line of treatment is not feasible due to soft tissue interposition, bone overriding and fibrous tissue formation around the fracture site. In these patients, there is also associated knee joint stiffness and shortening which has to be corrected. Neglected cases of fracture of the shaft of femur are treated with open reduction and internal fixation with interlocking intramedullary nailing. The advantages of open nailing in these patients include, easier attainment of absolute anatomical reduction, precise interdigitation of the fracture fragments which improves rotational stability, ease of opening of the medullary canals of the sclerotic bone and rare incidence of rotational mal-alignment. Hence, open reduction and internal fixation with intramedullary interlocking nailing is now considered the treatment of choice for neglected fractures of the shaft of femur, as evidenced by several studies. ${ }^{11-14}$.

In our present study, we evaluated the effectiveness of single stage open interlocking intramedullary nailing in neglected fracture shaft of femur patients through the assessment of attainment of union of the fracture and functional results of the limb. 
This was a prospective observational study conducted on patients of either sex with an average age of 26 years with the diagnosis of neglected fracture shaft of the femur (Table 1). All the patients underwent a single stage open interlocking intramedullary nailing (Figure 1a-1e). No external bone graft was used, only the callus removed from fracture site was reinserted (Figure 1b). The patients were followed up for a period of 1 year with serial radiographs and measurement of range of motion of the knee. All the patients achieved union of their fractures with an average duration of 22.6 weeks (Figure 1f, Table $5)$, the average range of motion of the knee improved from 34 degrees in the preoperative period to 114.5 degrees in the postoperative period and all the patients attained a reasonably good functional status of their limbs (Table 5). There were no neurovascular complications and limb length discrepancies in any of our patients. Two of our patients developed superficial infections at the surgical site which resolved with local drainage and antibiotics. Four of our patients had residual stiffness. Three of the four improved with physiotherapy and continuous passive motion, while one patient required quadricepsplasty for attainment of functional range of motion.
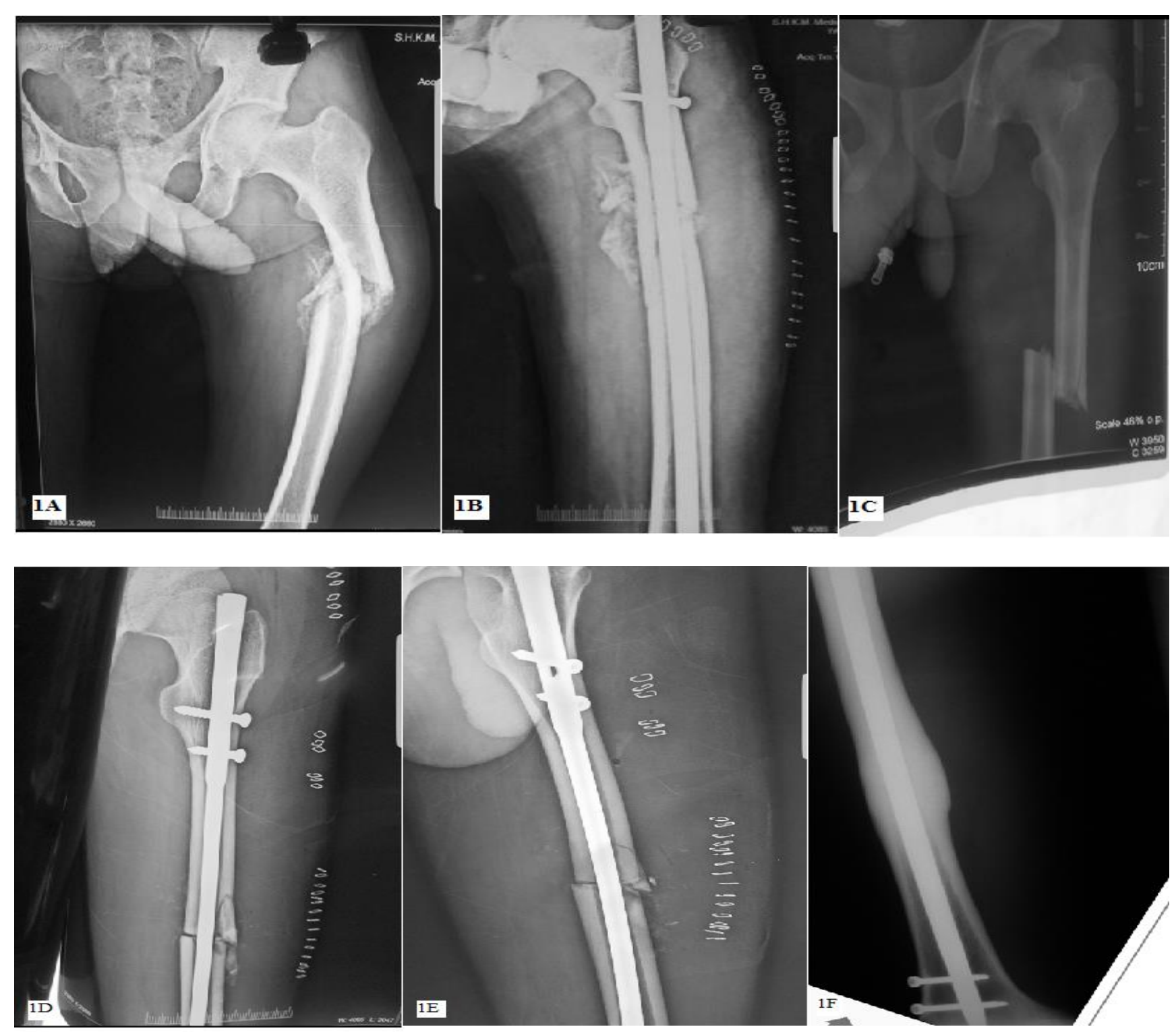

Figure 1: A: Preoperative radiograph of a patient with neglected 12 week old fracture shaft of femur left. B: Postoperative radiograph of the same patient after open reduction and internal fixation with interlocking intramedullary nailing. C: Preoperative radiograph of a patient with neglected 8 week old fracture shaft of femur left. D: Postoperative anteroposterior radiograph of the same patient after open reduction and internal fixation with interlocking intramedullary nailing. E: Postoperative lateral radiograph of the same patient after open reduction and internal fixation with interlocking intramedullary nailing. F: Anteroposterior radiograph of a patient at a follow up of 1 year showing union after open reduction and internal fixation with interlocking intramedullary nailing. 
The results of our study are quite comparable to other studies done about this procedure. ${ }^{8,15}$ The study by Boopalan et al was conducted on 17 patients while our study was conducted on 20 patients, the average time to union was 16 weeks while in our study it was 22.6 weeks which is favourably comparable. ${ }^{8}$ The study by Akinyoola et al was conducted on 52 patients and average time to union was 20 weeks, though the sample size of this study was much larger than our 20 patients, but its results compare quite favourably to our study. ${ }^{15}$

\section{CONCLUSION}

From the above analysis, we can infer that single stage open intramedullary nailing is a safe and highly effective surgical procedure for the management of neglected shaft femur fractures with high rates of union and excellent functional results.

\section{Funding: No funding sources}

Conflict of interest: None declared

Ethical approval: The study was approved by the institutional ethics committee

\section{REFERENCES}

1. Chapman MW. Closed intramedullary nailing of femoral-shaft fractures: technique and rationale. Contemp Orthop. 1982;4:213.

2. Clawson DK, Smith RF, Hansen ST. Closed intramedullary nailing of the femur. J Bone Joint Surg. 1971;53:681.

3. Hansen ST, Winquist RA. Closed intramedullary nailing of the femur: Küntscher technique with reaming. Clin Orthop Relat Res. 1979;138:56.

4. Veith RG, Hansen Jr ST. Closed intramedullary nailing of femoral-shaft fractures following reaming: technique and rationale. Contemp Orthop. 1982;4:41.

5. Benirschke SK, Melder I, Henley MB, Routt ML, Smith DG, Chapman JR, et al. Closed interlocking nailing of femoral shaft fractures: assessment of technical complications and functional outcomes by comparison of a prospective database with retrospective review. J Orthop Trauma. 1993;7:118.

6. Schatzker J. Open intramedullary nailing of the femur. Orthop Clin North Am. 1980;11:623.

7. Whittaker RP, Heppenstall B, Menkowitz E, Montique F. Comparison of open vs closed rodding femurs utilizing a Sampson rod. J Trauma. 1982;22:461.

8. Booplan PR, Sait A, Jepegnanam TS, Mattai T, Varghese VD. The efficacy of single-stage open intramedullary nailing of neglected femur fractures. Clin Orthop Relat Res. 2014;472(2):759-64.

9. Onuminya JE. The role of the traditional bonesetter in primary fracture care in Nigeria. S Afr Med J. 2004;94:652-8.

10. Onuminya JE, Onabowale BO, Obekpa PO, Ihezue $\mathrm{CH}$. Traditional bone setter's gangrene. Int Orthop. 1999;23:111-2.

11. Akinyoola L, Orekha O, Odunsi A. Open intramedullary nailing of neglected femoral shaft fractures: indications and outcome. Acta Orthop Belg. 2011;77:73-7.

12. Gahukamble A, Nithyananth $M$, Venkatesh $\mathrm{K}$, Amritanand R, Cherian VM. Open intramedullary nailing in neglected femoral diaphyseal fractures. Injury. 2009;40:209-12.

13. Mahaisavariya B, Laupattarakasem W. Late open nailing for neglected femoral shaft fractures. Injury. 1995;26:527-9.

14. Mukherjee SK, Jain V. Neglected femoral diaphyseal fracture. Clin Orthop Relat Res. 2005;431:72-9.

15. Akinyoola L, Orekha O, Odunsi A. Open intramedullary nailing of neglected femoral shaft fractures: indications and outcome. Acta Orthop Belg. 2011;77:73-7.

Cite this article as: Jan WF, Jahan A, Dar MY, Bangaroo FA, Khan I. A study on management of neglected shaft femur fractures by open intramedullary nailing. Int J Res Orthop 2018;4:667-71. 